\title{
ГСом \\ Speaking with one voice for climate science - climate researchers' opinion on the consensus policy of the IPCC
}

\section{Imke Hoppe and Simone Rödder}

Abstract

Keywords

DOI

Introduction
The Intergovernmental Panel on Climate Change (IPCC) proceeds on the assumption that scientific consensus is a tool for successful climate communication. While 'speaking with one voice' has contributed to the Panel's success in putting climate change on the public and political agenda, the consensus policy is also contested, as our literature analysis $(n=106)$ demonstrates. The arguments identified thereby inform a survey of climate scientists $(n=138)$, who are the ones responsible for realising the policy. The data indicate moderate support for the consensus policy but significantly more in traditional climate sciences than in social sciences, life- and geosciences.

Environmental communication; Science and policy-making

https://doi.org/10.22323/2.18030204

Submitted: 14th July 2018

Accepted: 21st March 2019

Published: 14th June 2019

In 2007, the Nobel Peace Prize was awarded jointly to the Intergovernmental Panel on Climate Change (IPCC) and former U.S. Vice President Al Gore "for their efforts to build up and disseminate greater knowledge about man-made climate change, and to lay the foundations for the measures that are needed to counteract such change." [The Norwegian Nobel Institute, 2018]. The Prize rewarded the Panel's success in putting "the climate problem" on the global political agenda which scholars have also acknowledged [Gupta, 2010; Beck, 2009; Beck, Borie et al., 2014; Solomon and Manning, 2008].

Since its establishment as a global science-policy interface in 1988, the IPCC proceeds on the assumption that scientific consensus is a tool for successful climate communication, and eventually, climate governance. The Panel is the top layer of a "climate knowledge infrastructure" [Edwards, 2010] with global temperature indicators and global climate models as essential components of consensus-making [Hulme, 2010, p. 562]. By 'speaking with one voice for global climate science' - combining highly diverse climate-related knowledge and including expertise from all over the world - the IPCC's assessment and knowledge 
synthesis gained legitimacy and authority for policy advice [Beck, Borie et al., 2014; Hulme, 2013].

However, this principle of consensus-based decision-making is often criticised [Beck, Borie et al., 2014; Bray, 2010; Curry and Webster, 2011; Haag, 2008; Victor, 2015; Oppenheimer et al., 2007; Masood, 1996]. It is argued that the consensus principle leads to a minimum of accepted outcome ["lowest common denominator" Beck, Borie et al., 2014]. The presentation of a plurality of viewpoints in the reports is favoured instead [Curry and Webster, 2011; Beck, Borie et al., 2014]. According to Oppenheimer et al. [2007], the consensus principle might downplay or exclude more extreme findings, which could be of help to understand the entire complexity of the climate system after a basic consensus is established. By trying to establish a consensus on climate change, the IPCC is arguably even making a case for climate change denial [Hulme, 2013]. Even lead authors in the fourth Assessment Report have criticised that "in the effort to reach consensus, some key details and high-risk scenarios were not fully explored" [Haag, 2008, p. 5]. Despite this criticism, the Panel's initial agenda-setting success led many to hope that scientific consensus is able to facilitate political action on anthropogenic climate change by providing a shared baseline of evidence [Jasanoff, 2011]. "The idea is to condense the knowledge of many experts into a single point of view that can settle disputes and aid policy-making." [Sarewitz, 2011, p. 7].

The IPCC thus is a case in point for interesting yet underexplored questions in science communication, namely how the science community assesses the consensus principle, e.g., in how far the establishment and communication of scientific consensus is indeed perceived as influential in public and policy debates. Besides a survey among IPCC WGI authors ("Working Group I" responsible for the report "The Physical Science Basis") [Stocker and Plattner, 2014], there is as of yet no systematic study of the climate community's opinion on the IPCC and its policy to speak with one voice. This paper aims to fill this gap by way of an online-survey of climate researchers in Northern Germany. We surveyed scientists working in traditional climate sciences, life- and geosciences as well as economists and social scientists because we assume that their diverse disciplinary backgrounds may help explain their respective opinion, and tested statistically for differences between the epistemic cultures in the sample. The survey was informed by a cross-disciplinary literature review on the panel and its reports and was conducted among climate researchers working in a German research consortium $(n=138,54 \%$ response rate, July-September 2015). In the following, we describe the IPCC as a science-policy interface, the role of consensus in the IPCC process and present arguments pro and contra the consensus policy based on a literature review. Subsequently, we discuss our empirical findings.

The IPCC as a science-policy interface
The Intergovernmental Panel on Climate Change (IPCC) was founded in 1988 by the World Meteorological Organization (WMO) and the United Nations Environment Programme (UNEP). Its aim and mission is to analyse the latest knowledge about Earth's changing climate [Schiermeier, 2011] and to "advise governments, its sponsors and the United Nations system as a whole on climate policy, and to update and assess relevant scientific information regularly and point out its policy implications." [Boehmer-Christiansen, 1994, p. 140]. The organisation and its assessment reports thus constitute a science-policy interface [Tollefson, 
2010; Geden, 2015; Gupta, 2010; Gupta, 2014; Beck, 2009]. The first IPCC assessment report (FAR) was published in 1990. According to policy scholars, it "provided the initial consensus knowledge on climate change" [Gupta, 2010, p. 637]. Subsequent reports were published in 1996 (SAR), 2001 (TAR), 2007 (AR4) and in 2013/2014 (AR5).

The actual assessment relies on hundreds of government-nominated authors involved in the production of the reports and organised in three overarching Working Groups, concerned with the physical science base (WGI), climate change impacts (WGII), and mitigation options (WGIII) respectively. Economists and some social scientists contribute mainly to WGIII.

The consensus-based decision-making is implemented in the working procedures through the review process to ensure "a high degree of consensus amongst authors and reviewers regarding the results presented" [Houghton in Hulme, 2013, p. 142]. The general reports of each Working Group consist of more than 1,000 pages each (for AR5) which are in a final step condensed to only 30 pages of "summary for policymakers" (SPM). This voluntary effort combines the "art of assessment making" [Edenhofer, 2014, p. 14] with traditional means of scientific quality control such as peer review. For AR5, the representation of consensus in agreement and evidence in the report has been standardised [Mastrandrea et al., 2010].

The Panel takes major decisions at plenary sessions involving government representatives and experts from the IPCC's 195 member countries, which is near-universal state membership [Gupta, 2014, p. 158]. These decisions include line-by-line approval of SPMs and thereby acceptance of the underlying report.

However, about a decade after the Nobel Prize, the Panel's assessment reports coexist with vastly different climate policies [Jasanoff, 2011; Beck, 2012], and the Panel itself has been repeatedly criticised. Public and scientific debates focus on the policy impact of the IPCC assessment reports [Beck, Borie et al., 2014; Gupta, 2014], on the way the Panel communicates its findings [Barkemeyer et al., 2015; Stocker and Plattner, 2014] and on critiquing the IPCC process [Griggs, 2014; Hughes and Paterson, 2017]. Social scientists have critically examined the history of the Panel [Agrawala, 1998a; Agrawala, 1998b], its ambiguous role in influencing societal views on climatic change [Hughes, 2015] and most recently its role in making (rather than mere forecasting) climate futures [Beck and Mahony, 2017; Kowarsch et al., 2017]. Not least, the consensus policy has been contested [e.g. Beck, Borie et al., 2014; Bray, 2010; Curry and Webster, 2011; Haag, 2008; Victor, 2015;

Oppenheimer et al., 2007; Masood, 1996].

The consensus policy revisited
To map the discourse on the IPCC consensus policy and to inform the survey, a literature review was carried out. Therefore, the study aims to condense the main arguments raised in the literature on the IPCC and - in a second step - operationalise the arguments as one or more items/questions, depending on how much sub-dimensions the respective argument integrates (for details, see chapter "Methodology and Study Design"). A combination of 'IPCC' and a second search term ('debate', 'controversy', 'trust', 'history', 'reputation', 'AR5', 'AR4', 'TAR', 'SAR', 'FAR', 'scientist') was used in seven databases (ISI Web of Science, Google Scholar, nature.com, Nature, Nature Climate Change, Nature News, and 
Science). Pertinent articles were then selected manually to ensure that they deal with an assessment of the IPCC regarding its workings, relevance in science, science-policy interaction, role in public discourse, and its future. 106 publications were considered, many of them published in the comment section or policy fora of scientific journals. By classifying the arguments raised, we mapped the discussion on the current state of the IPCC and its future directions. Within this process, the consensus policy was a major crosscutting theme, key to understanding the science-policy interaction, and the IPCC's role in public communication.

In the following, we introduce key arguments from the literature, and classify them into pros and cons, as they stress strengths or weaknesses of the consensus principle. We are thus not concerned with the question whether a sound scientific consensus on climate change exists [Oreskes, 2004; Bray, 2010], how it is established [Hughes and Paterson, 2017], whether it can be quantified [Cook et al., 2013], and why we can trust it [Oreskes, 2018], but solely with the question how the establishment and communication of a consensus view is perceived in the literature and, subsequently, by climate scientists.

\section{Arguments in favour of the consensus policy ('pros')}

Consensus reports such as those of the IPCC' and the Intergovernmental Science-Policy Platform on Biodiversity and Ecosystem Services (IPBES)'s are the "bedrock of science-based policy making" [Sarewitz, 2011] in areas where problems are 'wicked' in nature, i.e. they defy solutions that are timely, measurable, and implementable [Grundmann, 2016]. "By positioning all actors on a baseline of shared knowledge", the reports are expected to at least move these wicked problems "toward the low-conflict, strong-consensus end of the political action spectrum." [Jasanoff, 2011, p. 129]. While sociologists such as Grundmann, Jasanoff and Sarewitz caution against this policy (see below), advocates among climate scientists have long spoken out for communicating consensus in environmental assessment reports. The late Stephen H. Schneider, a high-profile U.S.-American climate scientist, stated: "The public is often so confused by the media's dutiful reporting of polarized extreme views (or their attempts to 'balance' the conclusions of a 500-scientist assessment with a few outlier Ph.D.s who say "It ain't so!") that political leaders ask groups such as [...] the IPCC to help society sort out where current consensus really lies." [2001, p. 339].

This first argument in favour of the consensus policy points to the strength of having established a highly reliable "climate knowledge infrastructure" [Edwards, 2010; Griggs, 2014; Nature, 2013]. It is mirrored in the IPCC's self-description, in which the organisation states that the reports provide "a clear and up to date view of the current state of scientific knowledge relevant to climate change" [The Intergovernmental Panel on Climate Change (IPCC), 2018]. It is indeed the report's up to date, comprehensive, and authoritative statements [Griggs, 2014, p. 171; Gupta, 2014], its rare errors [Griggs, 2014; Nature, 2013] and its success in strengthening interaction between politics and science [Schiermeier, 2014] that are acknowledged in the literature as the IPCC's core strength. ${ }^{1}$

\footnotetext{
${ }^{1}$ In the history of the IPCC, however, it was not always possible to live up to that standard: In this regard, 2007 was a watershed year for the IPCC. On the one hand, as already mentioned, the organisation was awarded the Nobel Prize for its success in increasing the focus on climate change
} 
This leads to the second argument, which stresses that the IPCC's assessment and knowledge synthesis through scientific consensus gained legitimacy and authority for policy advice. On the one hand, climate scientists see consensus as an "independent prior variable" for policy legitimacy and regulatory action [van der Sluijs et al., 1998, p. 293]. On the other hand, the IPCC's knowledge base is said to be acceptable for policy-makers only "if it is widely perceived to represent a highly credible and unbiased consensus" [Schrope, 2001, p. 112]. The omission of extreme values and opinions at both ends of the spectrum might thus be interpreted as a strength of IPCC assessments [Schrope, 2001], as it is also common practice to exclude outliers in data analysis. If one looks at the climate community as a Gaussian distribution, the value or opinion which is most accepted as the current state of knowledge might be the best choice to be communicated in a policy-relevant assessment.

In direct science-policy-interaction, the process of consensus-based decision-making, namely the negotiation of SPMs in the IPCC plenaries including the acceptance of the underlying full reports, is furthermore acknowledged as creating joint problem-ownership between science and politics. "Demanding line-by-line approval of its summary [...] is critical for its [the report's, the authors] value to policymakers. This process ensures that key conclusions are accepted by all governments and expressed in language that is both scientifically accurate and useful to policy." [Solomon and Manning, 2008, p. 1457].

A third argument emphasises a positive effect of the assessment process for science itself — the consensus strategy may help to combine highly diverse climate-related knowledge and to integrate expertise from all over the world. Kintisch [2013] and Bolin and Houghton [1995], for instance, praise the IPCC for facilitating interdisciplinary and international research and for improving of climate modelling. Moreover, specific science such as the Climate Model Intercomparison Project (CMIP) is conducted to prepare the report [Haag, 2008, p. 6].

\section{Arguments against the consensus policy ('cons')}

While consensus reports aim to facilitate policy-making in a certain field, the process of achieving consensus might act against this goal and even "undermine the very authority it seeks to project" [Sarewitz, 2011, p. 7]. This is because expert disagreement is the most everyday ingredient of a scientist's life, and therefore establishing a consensus and communicating "with one voice" are rather seen as unscientific: "If scientists are doing their job, then 'more research' in the short term is invariably a prescription for raising new questions, problems, and uncertainties - for preventing, not achieving consensus." [Sarewitz, 2000, p. 85]. Social scientists have therefore come up with a number of arguments against the consensus diplomacy of the IPCC.

A first argument is that by excluding a plurality of views and "focusing on consensus, the IPCC becomes vulnerable to criticism relating to issues where no consensus exists" [Beck, Borie et al., 2014, p. 83]. "A claim of scientific consensus

[Solomon and Manning, 2008], a highly publicised event that boosted the organisation's recognition as "climate change icon" [Haag, 2008, p. 4; see also Gupta, 2010]. On the other hand, its credibility was compromised by two events: By disclosure of several mistakes in AR4, especially the so-called Himalayan glacier melt error, and by publication of leaked-out email correspondence between IPCC scientists commonly known as Climategate [e.g. Gupta, 2010, p. 648]. 
creates a public expectation of infallibility that, if undermined, can erode public confidence" [Sarewitz, 2011, p. 7]. Consensus-based reports may lead to conservative estimates of climate change [Biello, 2007]. Furthermore, the principle excludes diverse or opposite findings and thereby oversimplifies [Curry, 2013]. The extremes are said to be ill-documented because "minimizing the importance of key structural uncertainties in underlying processes is a frequent outcome of the drive for consensus" [Oppenheimer et al., 2007, p. 1505]. By focussing on anthropogenic influence and excluding other reasons for climatic change, the IPCC is said to compromise scientific integrity [Geden, 2015] and even accused of decreasing both political activity and the scientific understanding of climate change and its implications [Curry, 2013]. According to Socolow [2011] and Jones [2000], it is necessary to also communicate high-consequence outcomes even with low probability as well as disagreement associated with estimated probabilities. These suggestions are in line with Hoag [2010] and Hulme et al. [2010] who criticise that the IPCC promotes homogeneity of thinking. A related concern are backlashes on climate science: "Scientists with a perspective that is not consistent with the consensus are at best marginalised (difficult to obtain funding and get papers published by 'gatekeeping' journal editors) or at worst ostracised by labels of 'denier' or 'heretic." [Curry, 2013, np].

A second argument - also related to backlashes on climate science - is that the consensus process with all its iterations ties up a lot of volunteer scientific and personal resources [Beck, Borie et al., 2014; Bray, 2010; Curry and Webster, 2011; Haag, 2008; Victor, 2015; Oppenheimer et al., 2007; Masood, 1996]. The assessment relies on the commitment of thousands of authors and reviewers worldwide; the major product is an assessment of already existing knowledge, not the production of new knowledge. Beck and colleagues argue that the consensus principle is highly resource intense while leading to a minimum of accepted outcome ["lowest common denominator” Beck, Borie et al., 2014, p. 82; referring to Rahmstorf, 2013].

Eventually, "the mere fact that scientists are speaking as if with one voice on a particular issue may be highly relevant, but not dispositive, when it comes to persuading global publics of the need to act." [Jasanoff, 2011, p. 131]. In contexts of mitigation and adaptation strategies, the consensus approach is, thirdly, criticised for constraining political options [Beck, Borie et al., 2014; Curry, 2013]. "By restricting the diversity of voices and closing down the range of options open to negotiation, consensus-based knowledge assessment procedures constrain the room for manoeuvre and limit innovation." [Beck, Borie et al., 2014, p. 84]. This is echoed by Sarewitz: "The commitment to consensus therefore comes at a high price: the elimination of proposals and alternatives that might be valuable for decision-makers dealing with complex problems." [2011, p. 7]. According to Victor [2015], the IPCC needs to be more engaged with the social sciences because the current bias towards economics and natural sciences decreases the efficiency and usefulness of the reports especially concerning mitigation and adaptation research and even undermines its purpose of being valuable for policy-making.

To sum up, the literature review shows that many analysts from the social sciences are critical of the consensus policy while eminent climate scientists as well as some social scientists focus on the communicative and political advantages of scientific consensus. We were thus interested in a broader view from the climate community, and ask the research question: How do working climate scientists perceive and evaluate the establishment and communication of an IPCC consensus? 
Methodology and study design

To answer the research question, we surveyed scientists working in a German research consortium, including scientists from traditional climate sciences, life- and geosciences and economics and social sciences $((\mathrm{N}=250 ; n=138$; response rate $54 \%$, July-September 2015). Our case study includes a variety of research organisations and a multitude of disciplines and hereby grasps the research organisation and multidisciplinarity of today's climate sciences [Deutsches Klima Konsortium, 2015; Beck, Böschen et al., 2013]. The online survey was pre-tested and implemented in UniPark (ISO 27001 certified). Respondents were associated with disciplines by way of self-attribution in the survey questionnaire ("In which discipline do you currently work?", response options see Figure 2, appendix A). To allow for statistical analysis, disciplines were grouped into three epistemic cultures, namely traditional climate sciences, life- and geosciences and economics and social sciences (see Table 1).

Table 1. Sample description $(n=135)$.

\begin{tabular}{|c|c|c|c|c|c|}
\hline \multicolumn{2}{|c|}{ IPCC Participation } & \multicolumn{2}{|l|}{ Gender } & \multicolumn{2}{|l|}{ Status } \\
\hline Participation & $23 \%(31)$ & Female & $29 \%(38)$ & Professor & $24 \%(29)$ \\
\hline \multirow[t]{4}{*}{ No Participation } & $77 \%(101)$ & Male & $58 \%(77)$ & Senior Scientist & $21 \%(25)$ \\
\hline & & & & Post Doc & $26 \%(22)$ \\
\hline & & & & Doctoral Candidate & $32 \%(27)$ \\
\hline & & & & Other Position & $7 \%(8)$ \\
\hline \multicolumn{6}{|c|}{ Discipline (self-attribution) } \\
\hline Meteorology & 28 & Geography & 13 & Sociology & 6 \\
\hline Oceanography & 20 & Geology & 6 & Political Sciences & 1 \\
\hline Mathematics & 1 & Soil Science & 6 & Agricultural Economics & 3 \\
\hline Physics & 2 & Biology & 4 & Journalism & 2 \\
\hline Computer Sciences & 3 & Renewable Energy & 2 & Media Sciences & 4 \\
\hline Other related Fields & 6 & Other related field & 6 & Other related field & 4 \\
\hline \multicolumn{6}{|c|}{ Epistemic Culture } \\
\hline \multicolumn{2}{|c|}{ Climate Sciences } & \multicolumn{2}{|c|}{ Life and Geo Sciences } & \multicolumn{2}{|c|}{ Economics and Social Sciences } \\
\hline In total & 60 & In total & 37 & In total & 20 \\
\hline In percent & $51 \%$ & In percent & $32 \%$ & In percent & $17 \%$ \\
\hline
\end{tabular}

Setting up the questionnaire and pre-testing

Based on the literature review, a dimensional analysis [see e.g., Kromrey, 2006] was conducted to make the literature review fruitful for the survey questionnaire. Additionally, this approach fosters unidimensionality and exhaustiveness of the items developed. Unidimensionality means that each question in the questionnaire should ask for only one aspect of a broader concept (e.g., "Perceived role of the IPCC in policy interactions"). Exhaustiveness means that the questions in sum cover the range of aspects belonging to this broader concept. The major, top-level dimensions were selected according to the research question and follow the distinction into 'pros' and 'cons' concerning the consensus policy.

The main 'pro' arguments in the literature identified and discussed in chapter XY are the following three: (a) "consensus produced a reliable climate knowledge infrastructure", (b) "consensus gained legitimacy and authority for policy advice" and (c) "consensus integrated expertise from different disciplines all over the world". A pro argument (a) addresses that consensus produces a reliable 
knowledge infrastructure, and is thus still much too broad to ask it in one single question. Thus, we differentiated here again into three indicators. The first indicator is (i) the "role of IPCC reports in scientific practice" to grasp in how far the IPCC has indeed become a major source for scientific practices, which should be verified by using and reading the IPCC reports ("Have you ever read an IPCC-report in full or in part? Please check all that apply."(filter)/"Which parts of the report did you read? Please check all that apply." "Which publication formats did you read in full or in part?"). A second indicator for (a) is the (ii) "overall evaluation (report and organization)" to understand in how far the IPCC is accepted in general ("Now we are interested in your personal, overall evaluation: What do you think about the IPCC reports in their current form?" / What do you think about the IPCC organization in its current form?"). A third indicator is the (iii) "representativeness of the report" to analyse as how reliable the scientists evaluate the IPCC reports for their respective field of expertise ("Is your field of research assessed in the IPCC reports?"(filter)/"In your opinion, is this assessment in the IPCC-reports representative of your field's state of knowledge?"). The sub-dimension (b) ("consensus gained legitimacy and authority for policy advice") asks in how far participants see an impact of the IPCC on different policy levels, namely the International Policy level, the European, the German and Hamburg's climate policy ("In your opinion, how weak or strong is the impact of IPCC reports on climate policy-making in the last 5 years? Please specify your answer for the following levels: international climate policy/European climate policy/German climate policy/Hamburg's climate policy."). For (c), which asks for the integration of knowledge, the motivation of scientists to read the report is of interest, because it reveals in how far the report has such function for working scientists (items see Table 2). Table 2 provides an overview on how the respective sub-dimensions are operationalised as items and the dimensions and sub-dimensions the questionnaire is focussed on.

The main 'con' arguments in the literature identified and discussed in chapter XY are the following three. First (a), we ask in how far the product of consensus-oriented effort, namely the IPCC report, is worth the edeavour ("In your opinion, are IPCC-reports worth the scientific effort?"), as this is heavily criticised in the related literature. Even if the literature was quite critical on this point, we took care for not formulating the question as critique, as this would probably distort the answers negatively. A second point and 'con' argument is that the consensus orientation leads to (b) conservative estimates of climate change and (c) constrains the room for (social) innovation. For (b), we asked "How do you evaluate the assessment?" with a scale ranging from too alarmist (5) to too conservative (1). For (c), two indicators are applied, namely how the consensus orientation (i) impacts debates in science itself ("In your opinion, how do IPCC reports impact debates in your field of research?") and in how far (ii) social sciences are equally represented ("In your opinion, are the social sciences adequately represented in the IPCC reports?").

An overall statement was designed to directly ask the participants for their opinion on the consensus policy ("In your opinion, is the IPCC's organizational policy to 'speak with one voice' for global climate science appropriate"? with 1=very appropriate and $5=$ very inappropriate").

All items were newly developed. To foster high construct validity, we conducted a two-step pre-test. Firstly, a draft version of the questionnaire was discussed with a range of experts in the field to ensure that the questions grasp the concern of the study and fit to the language and understanding of working climate scientists. 
Table 2. Dimensions and Sub-Dimensions of the Survey Questionnaire ('Pro arguments').

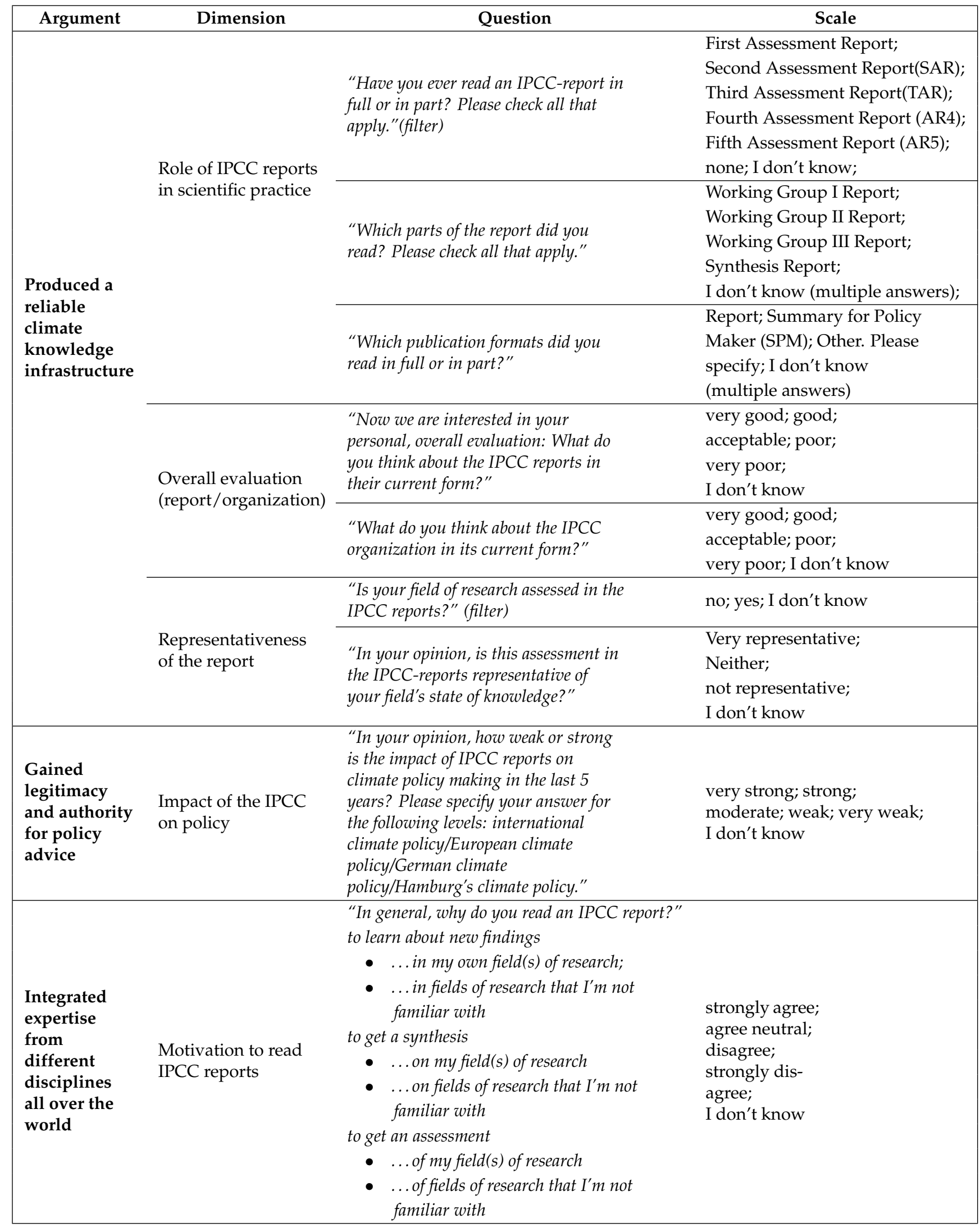


Table 3. Dimensions and Sub-Dimensions of the Survey Questionnaire ('Contra arguments').

\begin{tabular}{|c|c|c|c|}
\hline Argument & Dimension & Question & Scale \\
\hline Worth the effort & & $\begin{array}{l}\text { "In your opinion, are IPCC-reports } \\
\text { worth the scientific effort? }\end{array}$ & $\begin{array}{l}\text { yes, a great deal (5); in most } \\
\text { instances; somewhat; } \\
\text { very little; no, not at all (1); } \\
\text { I don't know }\end{array}$ \\
\hline $\begin{array}{l}\text { Conservative } \\
\text { estimates of climate } \\
\text { change }\end{array}$ & & $\begin{array}{l}\text { "How do you evaluate this } \\
\text { assessment?" }\end{array}$ & $\begin{array}{l}\text { too alarmist (5) } \\
\ldots \\
\text { appropriate } \\
\ldots \\
\text { too conservative (1) } \\
\text { I don't know }\end{array}$ \\
\hline \multirow{2}{*}{$\begin{array}{l}\text { Constrained the } \\
\text { room for (social) } \\
\text { innovation }\end{array}$} & $\begin{array}{l}\text { Impacts } \\
\text { debates in } \\
\text { science }\end{array}$ & $\begin{array}{l}\text { "In your opinion, how do IPCC reports } \\
\text { impact debates in your field of } \\
\text { research?" }\end{array}$ & $\begin{array}{l}\text { opens the space (5) } \\
\ldots \\
\text { has no effect } \\
\ldots \\
\text { narrows the space }(1) \\
\text { I don't know }\end{array}$ \\
\hline & $\begin{array}{l}\text { Representation } \\
\text { of Social } \\
\text { Science }\end{array}$ & $\begin{array}{l}\text { "In your opinion, are the social } \\
\text { sciences adequately represented in the } \\
\text { IPCC reports?" }\end{array}$ & $\begin{array}{l}\text { should be increased } \\
\ldots \\
\text { is appropriate } \\
\ldots \\
\text { should be decreased } \\
\text { I don't know }\end{array}$ \\
\hline
\end{tabular}

After a thorough revision, a second pre-test (think-aloud protocol) made sure that the questions were easy to answer and the phrasing understandable. A main 'lesson learned' in this phase was that open questions are very important so that respondents were able to explain and differentiate their answers. Additionally, an "I don't know" option for every single question was assessed as important.

Our field phase (July-September 2015) was in the aftermath of the publication of AR5 in 2013/2014, but during a period in which no general or special report was produced or published, i.e. there was no major external trigger from the IPCC to, for instance, talk about the IPCC with colleagues. Still, in the six months prior to our field phase (January-June 2015), two thirds of our respondents (61\%) talked to one or several colleagues about the IPCC, suggesting that the Panel is a generic topic for peer conversation.

When asked for their overall opinion on IPCC's policy of "speaking with one voice" for global climate science, we did not find a consensus view. Only half of the respondents $(50 \%)$ agree with the policy $(\mathrm{M}=3.2 ; \mathrm{SD}=1.2)$.), about one quarter $(27 \%)$ disagrees, one in ten neither agrees nor disagrees (11\%) and about one in ten $(12 \%)$ answers "I don't know". A t-test is applied to test if the three epistemic cultures (traditional climate scientists, economists and social scientists, life- and geoscientists) statistically differ with respect to this opinion $(t(77)=2.14, p=.035)$. The result demonstrates that the support is significantly stronger among traditional climate scientists $(\mathrm{M}=3.5 ; \mathrm{SD}=1.2)$ than among life- and geoscientists $(\mathrm{M}=2.8$; 
$\mathrm{SD}=1.2)$ as well as economists and social scientists $(\mathrm{M}=2.2 ; \mathrm{SD}=1.1)$. Further on the explanatory side, there is a significantly positive correlation between a higher degree of focus on climate change and the opinion on the consensus policy $\left(\mathrm{r}=.17^{*}\right)$.

In the following sections, we interpret the survey data with respect to the more differentiated pro and contra arguments on the consensus policy from the literature. Particular attention is paid to the question as to what extent these opinions can be explained by the epistemic cultures to which the surveyed scientists belong.

\section{Opinions on arguments in favour of consensus ('pros')}

The first argument stresses the role of the IPCC in a reliable global climate knowledge infrastructure [Edwards, 2010; Griggs, 2014; Nature, 2013]. Our questionnaire (see Table 2) applied three indicators to analyse how the scientific community perceives and evaluates the assessments provided by the Panel: 1 . the role of IPCC reports in scientific practice, 2 . the evaluation of the quality of the report, and 3. the representativeness of the report for the respective field of expertise. The first indicator applied is IPCC readership. In case the IPCC serves as the top layer of a "climate knowledge infrastructure", its reports should be widely received and read in the climate community. This is indeed confirmed by our survey data (see Figure 3, appendix A). The great majority of respondents have read an IPCC report or parts thereof $(89 \%)$. Only $11 \%$ have never read an IPCC report. A breakdown of the readership for the individual reports demonstrates how IPCC reports gradually gained reach and relevance in the climate community. The first report (FAR) in 1990 was read by a mere $17 \%$ of respondents. The most recent report, published in $2013 / 14$ (AR5), in contrast, was read by $68 \%$ of the respondents. Overall, $89 \%$ of respondents read the report, and about $11 \%$ did not.

Altogether, we find a 51\% increase in readership from FAR to AR5. This increase is only marginally explained by age: even in the group of scientists aged over 40, the readership grows considerably over time, while a few graduate students aged between 20 and 30 have read the FAR from 1990 (Table 5, appendix A). The disciplinary background of the non-readers reveals that these $11 \%$ non-readers come significantly less from traditional climate sciences (29\%) and life- and geosciences (32\%) than from economics and social sciences (43\%). As the preconditions for an ANOVA to test for significant differences are not fulfilled (both items are not normally distributed), a Kruskal-Wallis test is realised (Kruskall-Wallis $\mathrm{H}(2)=7.82 ; \mathrm{p}=0.020$; Cramers' $\mathrm{V}=0.259 ; \mathrm{p}=0.020$ ). Overall, the results regarding the report readership patterns demonstrate that over the course of the last 25 years, and especially since the TAR, the IPCC's assessment reports have taken centre stage in the broad and multidisciplinary field of climate sciences.

Our second indicator assesses the scientists' opinions on the overall quality of the IPCC reports. Here, the acceptance and relevance of IPCC assessments in the surveyed community becomes even more visible $(\mathrm{M}=2.2$; $\mathrm{SD}=0.7$ with $1=$ very good and $5=$ very poor). More than half of the respondents think of the reports as very good or good $(57 \%)$, a further $30 \%$ considers them acceptable. Open comments emphasise the review function of the report, e.g., "it is an excellent overview paper", and a "unique and very comprehensive state-of-the art-report in this field". 


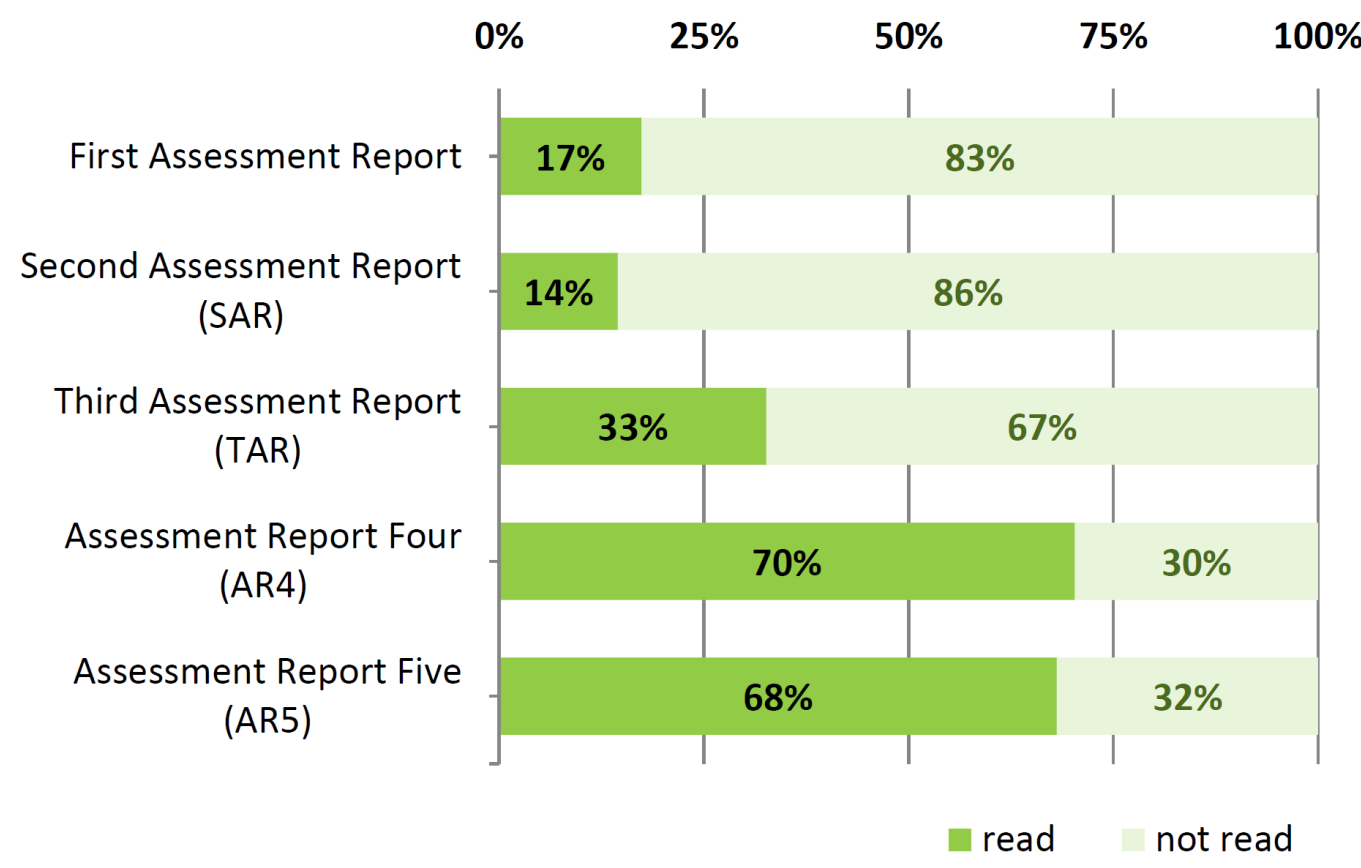

Note: $n=138$; multiple answers possible.

Figure 1. Question: "Have you ever read an IPCC-report in full or in part?"

Only $2 \%$ think of the reports as poor. The test reveals that all three epistemic cultures (traditional climate sciences, life- and geoscience, economics and social sciences) do not evaluate the report significantly differently (Kruskall-Wallis $\mathrm{H}(2)=$ $2.540, \mathrm{p}=.259$ ). Thereby we can conclude that the report is rated as very good in all three epistemic cultures surveyed. The (statistical) reason is the small variance, as nearly all respondents agree on a very good evaluation, these opinions are largely unaffected by epistemic culture.

The third indicator we use is the assessment of the representativeness of the report for the respondent's field of expertise. Here, our survey data confirm that climate researchers in general regard the reports as representative of their field's state of knowledge: a majority of $83 \%$ respondents agrees and only $7 \%$ disagrees with this statement $(\mathrm{M}=2.2 ; \mathrm{SD}=1.3 ; 5$-Likert scale with $1=$ =ery representative and $5=$ not representative). Again, there is no significant difference between epistemic cultures (Kruskall-Wallis $\mathrm{H}(2)=2.135, \mathrm{p}=.344$ ). This finding demonstrates that the IPCC report is widely accepted as representative for diverse research fields, a somewhat surprising result for the social sciences that requires further investigation.

All three indicators surveyed to analyse the researchers' opinion on the first pro argument confirm that in the eyes of the community the IPCC assessments are a reliable, representative top layer of the global "climate knowledge infrastructure" that is worth reading for any member of the community.

The second argument stresses that the IPCC's assessment and knowledge synthesis through scientific consensus gained legitimacy and authority for policy advice. For this reason, we were interested in learning in how far the surveyed community sees 
impacts of previous IPCC reports on climate policy-making at different governance levels. Specifically, we asked for influences on International, European, German and CITY's (anonymised) climate policy (see Figure 5, appendix A). Respondents feel that the strongest IPCC impacts are on the European (59\% see a (very) strong effect) and on the German level (58\% effect). Impacts on the international levels are evaluated as slightly weaker (45\%). As all indicators measuring the opinion on the IPCC's policy impact correlate positively with each other $\left(\mathrm{r}_{\min }=.36^{* * *}\right.$ to $\left.\mathrm{r}_{\max }=.73^{* * *}\right)$, they are integrated into one common index $(\mathrm{M}=3.3 ; \mathrm{SD}=0.9)$. Again, this assessment does not vary significantly between epistemic cultures (Kruskall-Wallis $\mathrm{H}(2)=3.540, \mathrm{p}=.170$ ).

The third argument sees positive impacts of the reports on the scientific fields they assess. The consensus process may help to combine highly diverse climate-related knowledge and to integrate expertise from all over the world. Hence, we asked for the individual motivations to read IPCC reports, and in how far the report indeed helps researchers to gain new knowledge and to get access to other disciplines than their own (for all items asked, see Table 2). We integrated all items into an explanatory factor analysis (Primary component analysis with varimax rotation; $81 \%$ explained variance; pairwise; all factor loadings $>0.3$; KMO-coefficient .56; $\mathrm{n}=95$; see Table 3). The first factor describes the motivation to be better informed about other and maybe new fields of research $(\mathrm{M}=4.1 ; \mathrm{SD}=0.7)$. The second factor is to be better informed of one's own field of research $(\mathrm{M}=3.9 ; \mathrm{SD}=0.9)$. The third motivation is public science communication $(\mathrm{M}=3.6$; $\mathrm{SD}=1.1)$. The fourth factor depicts that researchers, by learning who is contributing and who is cited, acquire information on their community $(\mathrm{M}=2.9 ; \mathrm{SD}=1.1)$. In sum, the strong overall agreement and slightly higher numbers for getting an assessment in other fields or learning about other fields' findings indicate that the reports are seen as facilitating knowledge integration in this multidisciplinary field.

The first factor (motivation to be better informed about other and maybe new fields of research) and the third factor (public science communication) do not differ significantly between the epistemic cultures in our sample. The situation is, however, different for the second factor (to be better informed of one's own field of research with $\mathrm{M}=3.9 ; \mathrm{SD}=0.9$ ): this motivation is significantly stronger in traditional climate sciences $(\mathrm{M}=3.9 ; \mathrm{SD}=0.8)$ and life- and geosciences $(\mathrm{M}=4.2 ; \mathrm{SD}=0.9)$ than in economics and social sciences $(\mathrm{M}=3.4 ; \mathrm{SD}=1.0)$ (Kruskall-Wallis $\mathrm{H}(2)=7.043, \mathrm{p}=$ .030); also the fourth motivation (gathering community-related information) is higher in traditional climate sciences and life- and geosciences than in social sciences (Kruskall-Wallis $\mathrm{H}(2)=5.908, \mathrm{p}=.050$ ). This is unsurprising as the reports are a major reference point in traditional climate sciences, but less so in life- and geosciences and a small specialty in the social sciences.

\section{Opinion on arguments against consensus ('cons')}

The first argument is that the establishment of a consensus actively excludes diverse or opposite findings so that the IPCC reports draw criticism on being too conservative or too alarmist. We have already shown that the vast majority of respondents think of the reports as being representative for their field's state of knowledge. This finding is in line with Rosenberg et al. [2010] who also found a general agreement of scientists with IPCC findings. Against the critiques, the 
Table 4. Motivation to read IPCC reports (factor analysis).

\begin{tabular}{|c|c|c|c|c|}
\hline Factor & $\begin{array}{l}\text { Content-related } \\
\text { for other } \\
\text { research field(s) }\end{array}$ & $\begin{array}{l}\text { Content-related } \\
\text { for own } \\
\text { research field(s) }\end{array}$ & $\begin{array}{l}\text { Public science } \\
\text { communication- } \\
\text { related }\end{array}$ & $\begin{array}{l}\text { Community- } \\
\text { related }\end{array}$ \\
\hline & 1 & 2 & 3 & 4 \\
\hline $\begin{array}{l}\text { To get a synthesis } \\
\text { on fields of research } \\
\text { that I'm not familiar with }\end{array}$ & .87 & & & \\
\hline $\begin{array}{l}\text { To learn about new findings } \\
\text { in fields of research } \\
\text { that I'm not familiar with }\end{array}$ & .86 & & & \\
\hline $\begin{array}{l}\text { To get a synthesis } \\
\text { on my field(s) of research }\end{array}$ & & .83 & & \\
\hline $\begin{array}{l}\text { To learn about new findings } \\
\text { in my own field(s) } \\
\text { of research }\end{array}$ & & .83 & & \\
\hline $\begin{array}{l}\text { To get an assessment } \\
\text { of my field(s) of research }\end{array}$ & & .83 & .32 & \\
\hline $\begin{array}{l}\text { To be prepared } \\
\text { for discussions with } \\
\text { journalists }\end{array}$ & & & .94 & \\
\hline $\begin{array}{l}\text { To be prepared } \\
\text { for discussions with the } \\
\text { public }\end{array}$ & & & .90 & \\
\hline To see who is contributing & & & & .88 \\
\hline To see who is cited & & & & .85 \\
\hline $\begin{array}{l}\text { Scale mean } \\
\text { (Standard deviation) }\end{array}$ & $4.1(0.7)$ & $3.9(0.9)$ & $3.6(1.1)$ & $2.9(1.1)$ \\
\hline Eigenvalue & 1.0 & 3.1 & 1.7 & 1.4 \\
\hline Cronbachs- $\alpha$ & .71 & .80 & .89 & .80 \\
\hline
\end{tabular}

Note: primary component analysis with varimax rotation; $81 \%$ explained variance; pairwise; all factor loadings $>0.3$; KMO-coefficient .56; $\mathrm{n}=95$; Scale Mean of all items on a 5-point-Likert scale of 1 "strongly disagree" to 5 "strongly agree". Items excluded due to double loadings: "... to be prepared for discussions with colleagues." and "to get an assessment in fields of research that I'm not familiar with."

framing of the assessment reports is evaluated as appropriate by the majority of respondents $(72 \% ; \mathrm{M}=3.0 ; \mathrm{SD}=0.5)$. Only one in ten climate researchers feels that the assessment is too alarmist $(10 \%)$, less than one in ten that it is too conservative $(7 \%)$, and about one in ten says s/he does not know (12\%). As expected with regard to an extremely low variance $(\mathrm{SD}=0.5)$ of this item, this view does not differ between epistemic cultures (Kruskall-Wallis $\mathrm{H}(2)=1.054, \mathrm{p}=.594$ ).

As an indicator to measure the influence of the consensus policy on scientific discourses, we asked the scientists in how far debates in their field of research are impacted by the IPCC ('opens the space for discussion' versus 'narrows the space for discussion'). A majority of $61 \%$ of our respondents say that the IPCC reports opens spaces for discussion in their field ( $\mathrm{M}=3.9 ; \mathrm{SD}=1.0) ; 18 \%$ say it has no effect, $7 \%$ say that the IPCC narrows the space for discussion in their research field and $14 \%$ say "I don't know". Interestingly, epistemic cultures do not differ significantly from each other (Kruskall-Wallis $\mathrm{H}(2)=2.323, \mathrm{p}=.313$ ). This finding is somewhat surprising, and an open comment may help to elucidate that. A researcher 
commented: "I think the IPCC reports have a strong potential to unify (make them more effective) scientific efforts and help avoid parallel structures in research because it is easier to understand what the necessary research directions are and who is doing what". In that statement, the IPCC's synthesis, assessment and political agenda-setting are unambiguously referred to as positive.

Second, the huge effort invested to reach a consensus raises concern. Critics have pointed out that the workload for the reports is no longer reasonable [Griggs, 2014]. In contrast, the majority of our respondents feel that the reports are worth the scientific effort ("yes, a great deal", 25\%, and "in most instances", $48 \%$; $\mathrm{M}=2.0$; $\mathrm{SD}=0.7$ with 1 "yes a great deal"). The data indicate that traditional climate scientists $(M=2.1 ; \mathrm{SD}=0.8)$ significantly feel more often that the IPCC reports are worth the scientific effort than life- and geoscientists $(\mathrm{M}=1.7 ; \mathrm{SD}=0.7)(t(81)=2.324$, $\mathrm{p}=.023)$. Economists and social scientists do not differ in their opinion from lifeand geoscientists $(t(52)=-1.465, \mathrm{p}=.149)$. There is also no statistical difference between traditional climate scientists and social scientists $(t(72)=0.307, \mathrm{p}=.739)$.

The third argument raises concern that consensus-based knowledge assessment procedures "constrain the room for manoeuvre and limit innovation." [Beck, Borie et al., 2014, p. 84] and that the social sciences are not well represented [Victor, 2015]. To evaluate how climate scientists think about this concern, we asked for the role of social sciences in the IPCC and whether they are appropriately represented in IPCC reports. The question receives a very high level (44\%) of "I don't know" responses $(\mathrm{M}=2.1 ; \mathrm{SD}=1.2)$. A third of the respondents $(33 \%)$ feel that the representation of social sciences in IPCC reports should be increased, for $16 \%$ it is appropriate, and $7 \%$ think it should even be decreased. The response to this question, including the high share of "I don't know"-answers, reflects the natural science-dominated composition of the surveyed community. It is noteworthy that regarding this question, the views of the epistemic cultures differ the most. The surveyed economists and social scientists favour an increased representation in IPCC reports $(\mathrm{M}=1.3 ; \mathrm{SD}=0.5)$ much more than their colleagues from life- and geosciences $(\mathrm{M}=2.2$; $\mathrm{SD}=0.9)$ and traditional climate sciences $(\mathrm{M}=2.8 ; \mathrm{SD}=1.4)$; the differences between these groups are highly significant (Kruskall-Wallis $\mathrm{H}(2)=15.261, \mathrm{p}=.000$ ).

\section{Conclusions}

Since the establishment of the IPCC as a science-policy interface, it is a key proposition in global climate governance that more findings with more certainty and greater consensus will more successfully inform policy-making. Because the IPCC has been such a successful agenda setter, expectations that the Panel would also be able to provide policy solutions are still high and fed by attempts to quantify how much scientific consensus there is [Oreskes, 2004; Oreskes, 2018; for a critique, see Pearce et al., 2017]. There is no rationale for such a linear model, neither on theoretical grounds [Luhmann, 1989] nor from observations of a practice in which "policy-makers view the IPCC reports mainly as a source of quotes with which to legitimize their preferences." [Geden, 2015; see also Geden and Fischer, 2014]. Instead, it might be more appropriate to think of scientific consensus as serving a policy function. Based on a comparison of the climate case with the case of ozone layer protection, Grundmann has argued that to achieve an ambitious political goal, scientific consensus is not a necessary precondition [2006], and Betsill and Pielke [1998] have concluded that it was indeed scientific uncertainty rather than scientific certainty that fostered political action in the ozone case. This triggers 
the question, in how far the establishment and communication of scientific consensus is indeed influential in public and policy debates. But so far, the consensus policy has been critically discussed mainly in the social science literature. In this paper, and as a first step towards a science of consensus communication, we were therefore interested in the climate community's opinion on the IPCC's policy 'to speak with one voice' and in how far opinions differ between epistemic cultures, namely traditional climate sciences, life- and geosciences, economics and social sciences.

Overall, the vast majority of the surveyed climate scientists value the content and framing of the IPCC's assessment reports, which are the result of a consensus-oriented process. Respondents think of the reports as being representative for their field's state of knowledge and appropriate (i.e. neither too conservative nor to alarmist) in their framing of climate change. This finding is in line with Rosenberg et al. [2010] who also found a general agreement of scientists with IPCC findings. Thus, a main result is that, according to our survey data, the epistemic cultures involved in climate research share an overall positive rating of IPCC reports. The data suggest that in the eyes of the surveyed community the IPCC'S assessments are a reliable, representative top layer of the global "climate knowledge infrastructure". The overall evaluation of the report is broadly good or very good in all surveyed disciplines.

There is, however, no common view on the consensus policy for climate communication: only half of the respondents agree with the principle of one global discursive IPCC voice that speaks for climate science (49\%) while the other half disagrees, is unsure or does not know. The critical discussion in the literature, while not constituting the majority opinion of our surveyed scientists, is thus somewhat mirrored in the scientists' own accounts. To analyse what is behind this overall statement, a range of specific pro and contra arguments were surveyed. It was tested, in how far these opinions differ between the epistemic cultures. All epistemic cultures share scepticism about the IPCC's influence on climate policy, especially on the global level. This scepticism is common ground and in line with the literature and practice-informed critique such as in Geden [2015]. With respect to backlashes on their own field of research, opinions are more positive and attribute to the IPCC process an 'opening up' of scientific discussions rather than narrowing them [as suggested e.g., in Hughes and Paterson, 2017]. This view is also shared between the three epistemic cultures surveyed but in stark contrast to the social science critique, and the results call for more in-depth qualitative studies of the politicization of climate research through its advisory function and advocacy.

Differences between the three epistemic cultures exist - not surprisingly — with regard to the role and value the IPCC reports have for a scientist's own work. The analysis of IPCC readership reveals that traditional climate scientists and life- and geoscientists read the reports more regularly than the surveyed social scientists and economists. Moreover, traditional climate scientists more often state that they read the IPCC reports to be better informed of their own field of research and to gather community-related information than their colleagues in the other two epistemic cultures. Similarly, they also feel significantly more often that the IPCC reports are worth the effort of producing them. 
The data indicate that, overall, the general support for the consensus policy is significantly stronger in traditional climate sciences than in life and geosciences and economics and social scientists. We interpret this finding with the idea that the synthesis and consensus-making bring a higher 'payback' for traditional climate scientists than for other disciplines, in form of a knowledge resource. This interpretation is strengthened by another result: the surveyed economists and social scientists wish an increased representation in IPCC reports to a much higher degree than their colleagues from traditional climate sciences and life- and geosciences.

In a broader perspective, our interpretation route leads to questioning in how far consensus is an appropriate tool and communication policy for climate sciences. We acknowledge that this is a far from trivial question, for traditional climate sciences and all the more so for the multi-paradigmatic social sciences. In the consensus diplomacy, dissent and uncertainty are treated as if they undermine the authority of the knowledge if widely shared - even though they are genuine features of the social process of scientific knowledge production. The consensus process which, includes several phases, multiple actors from many institutions and several rounds of comments and reviews, remains susceptible to the disclosure of negotiations and details of active 'consensus-making' (such as Climategate). But if the proposition is that experts disagree, what is the alternative to the IPCC's communication policy of polishing uncertainty and disagreement for public communication and policy advice?

It is an as of yet underexplored question how science communicators should deal with expert dissent and how they should evaluate it themselves (for an analysis of the case of the British Science Media Center, see Rödder [2015]). Sarewitz' argument might be an option: "The very idea that science best expresses its authority through consensus statements is at odds with a vibrant scientific enterprise. Consensus is for textbooks; real science depends for its progress on continual challenges to the current state of always-imperfect knowledge. Science would provide better value to politics if it articulated the broadest set of plausible interpretations, options and perspectives, imagined by the best experts, rather than forcing convergence to an allegedly unified voice." [Sarewitz, 2011, p. 7; similarly Hulme, 2013]. For future assessments, it might be worth exploring the alternative strategy of communicating plural views.

This paper is based on the research project "Reassessing an assessment: A study of the IPCC process", funded in the framework of CliSAP's competition of ideas from March to December 2015 (DFG EXC 177 CliSAP). We would like to thank Bärbel Langmann who greatly contributed her natural science perspective to the entire project. Moreover, we thank Silke Beck, Oliver Geden, Florian Rauser, Christiane Textor and Jens Wolling for contributing their respective expertise as members of the project's advisory board. We thank our student staff Torben Fließwasser, Lukas Lapschieß, Katharina Sabatzki and Maike Scheffold for their most helpful support throughout the project and Shorouk Elkobros for her assistance in preparing this manuscript for publication. We most gratefully acknowledge the contribution of all scientists who filled in the survey questionnaire and/or made themselves available for pre-test interviews. 
Appendix A.

Supplementary material

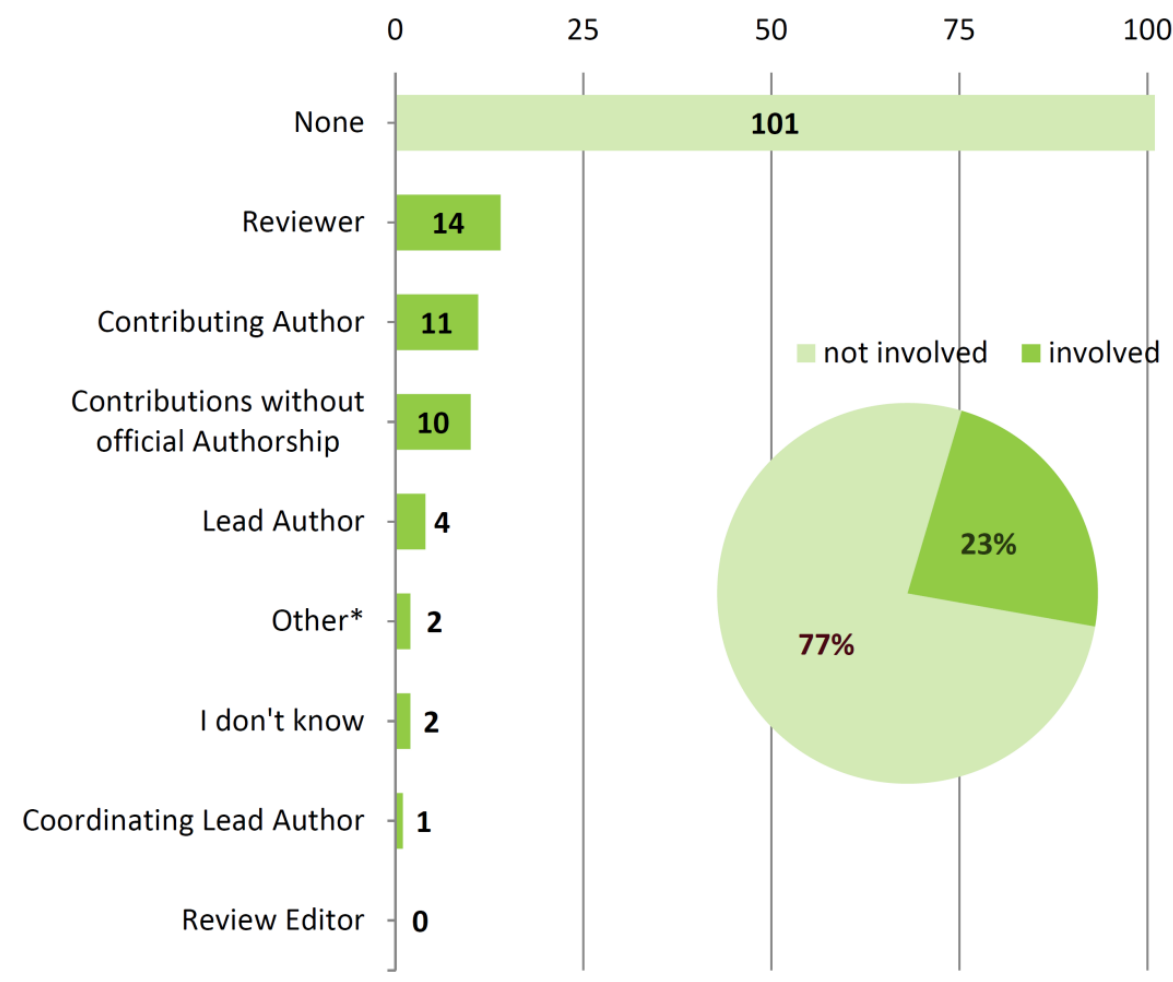

Note: $\mathrm{n}=138$; multiple answers possible; *Other: worked on consortia simulations/providing simulation data for the IPCC.

Figure 2. Question: "Have you ever been involved in the IPCC?"

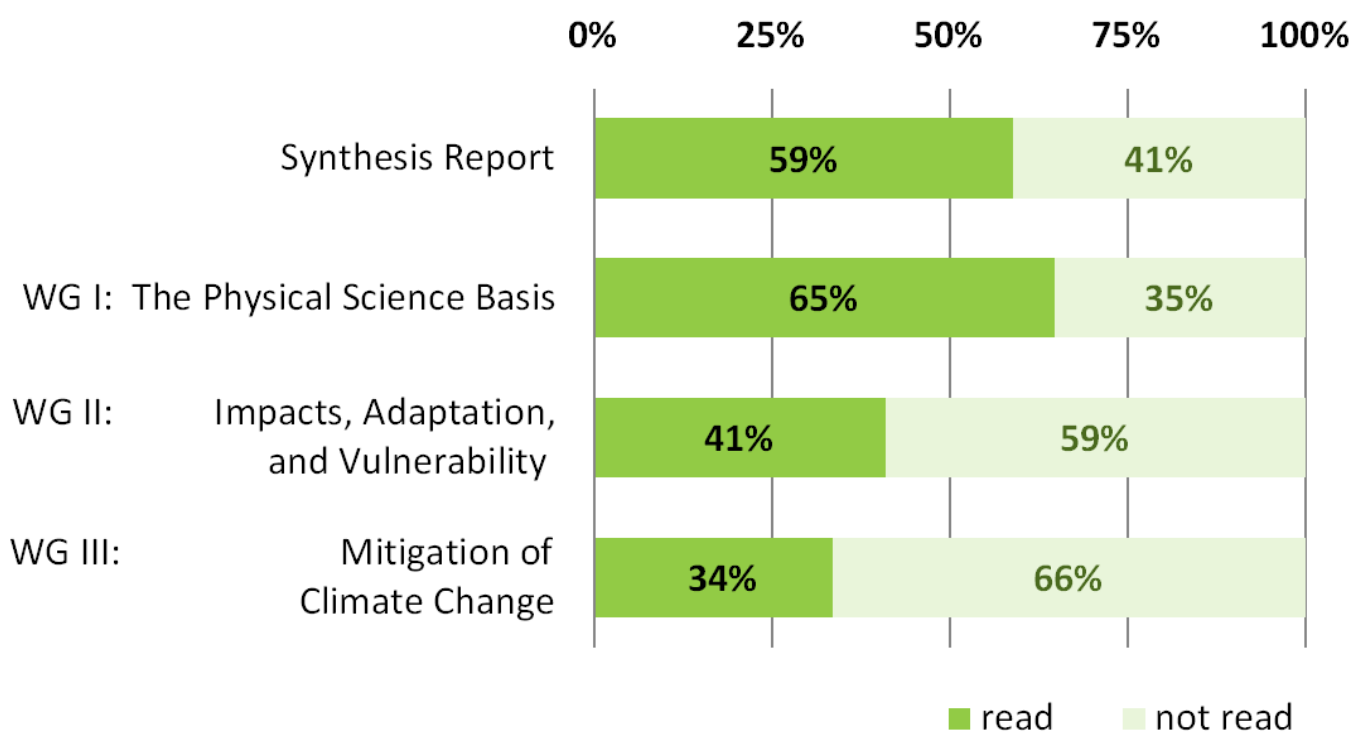

Note: $n=138$; multiple answers possible.

Figure 3. Question: “Which parts of the report did you read?" 


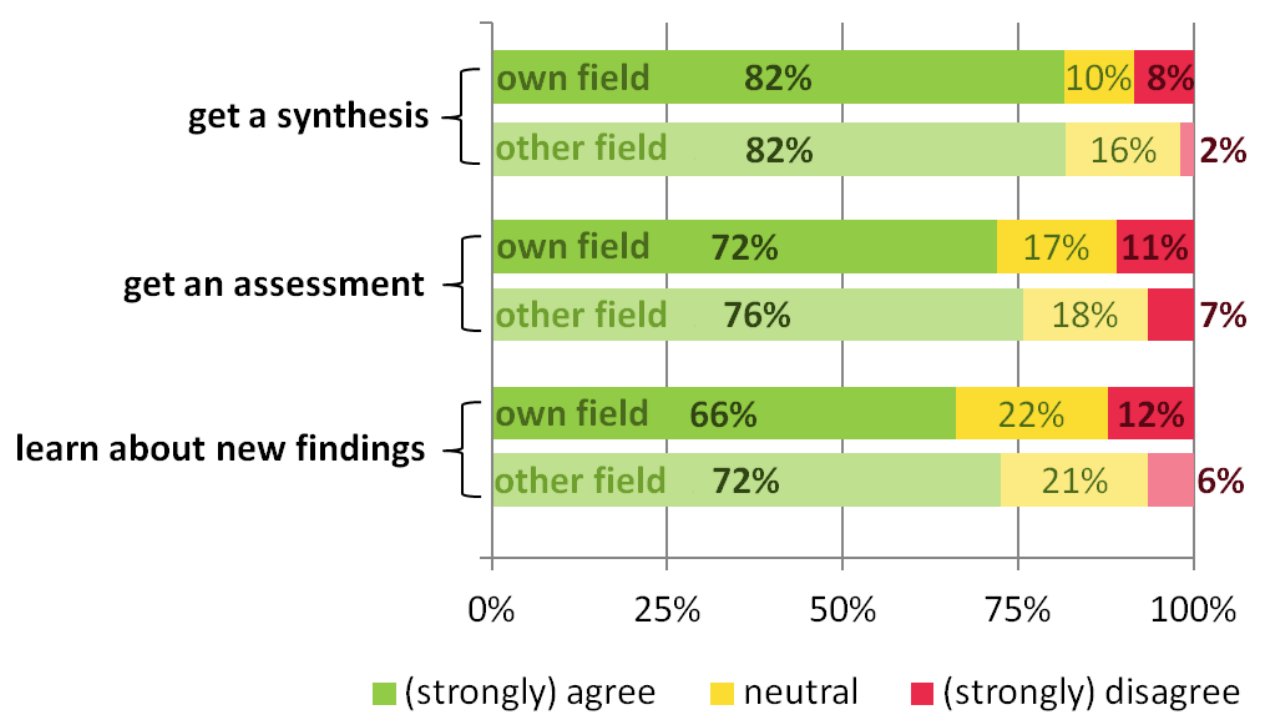

Note: $\mathrm{n}=109-119 ;$ 5-point-Likert scale from 1 "strongly disagree" to 5 "strongly agree"; $1+2$ recoded into "(strongly) disagree; $4+5$ recoded into "(strongly) agree".

Figure 4. Question: “In general, why do you read an IPCC report?”

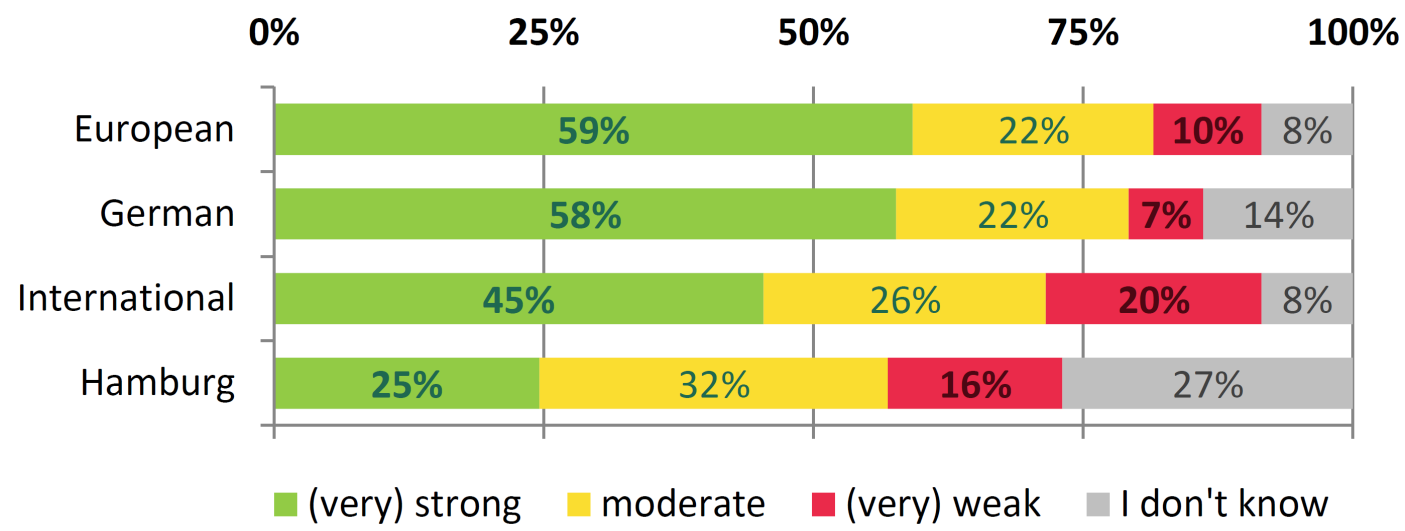

Note: $\mathrm{n}=94-118$; 5-point-Likert scale from 1 "very strong" to 5 "very weak"; $1+2$ recoded into "(very) strong"; $4+5$ recoded into "(very) weak".

Figure 5. Question: "In your opinion, how weak or strong is the impact of IPCC reports on climate policy making in the last 5 years?" 
Table 5. Report readership by age groups.

\begin{tabular}{|cccccc|}
\hline & $\begin{array}{c}\text { First } \\
\text { Assessment } \\
\text { Report }\end{array}$ & $\begin{array}{c}\text { Second } \\
\text { Assessment } \\
\text { Report }\end{array}$ & $\begin{array}{c}\text { Third } \\
\text { Assessment } \\
\text { Report }\end{array}$ & $\begin{array}{c}\text { Assessment } \\
\text { Report } \\
\text { Four }\end{array}$ & $\begin{array}{c}\text { Assessment } \\
\text { Report } \\
\text { Five }\end{array}$ \\
\hline $\mathbf{2 0 - 2 9}$ & 3 & Academic Background (Age) \\
$\mathbf{3 0 - 3 9}$ & 3 & 1 & 4 & 13 & 13 \\
$\mathbf{4 0 - 4 9}$ & 5 & 3 & 9 & 31 & 32 \\
$\mathbf{5 0 - 5 9}$ & 6 & 7 & 13 & 15 & 13 \\
$\mathbf{6 0 - 6 9}$ & 1 & 3 & 4 & 5 & 19 \\
No answer & 3 & 4 & 4 & 5 & 4 \\
\hline Total & $\mathbf{1 8}$ & $\mathbf{1 4}$ & $\mathbf{3 9}$ & $\mathbf{8 5}$ & $\mathbf{8 1}$ \\
\hline
\end{tabular}

Note: $n=138$; multiple answers possible.

\section{References}

Agrawala, S. (1998a). 'Context and early origins of the intergovernmental panel on climate change'. Climate Change 39 (4), pp. 605-620. https://doi.org/10.1023/A:1005315532386.

- (1998b). 'Structural and process history of the intergovernmental panel on climate change'. Climate Change 39 (4), pp. 621-642. https://doi.org/10.1023/A:1005312331477.

Barkemeyer, R., Dessai, S., Monge-Sanz, B., Renzi, B. G. and Napolitano, G. (2015). 'Linguistic analysis of IPCC summaries for policymakers and associated coverage'. Nature Climate Change 6 (3), pp. 311-316. https://doi.org/10.1038/nclimate2824.

Beck, S. (2009). Das Klimaexperiment und der IPCC: Schnittstellen zwischen Wissenschaft und Politik in den internationalen Beziehungen. Marburg, Germany: Metropolis.

Beck, S. (2012). 'The challenges of building cosmopolitan climate expertise: the case of Germany'. Wiley Interdisciplinary Reviews: Climate Change 3 (1), pp. 1-17. https://doi.org/10.1002/wcc.151.

Beck, S., Borie, M., Chilvers, J., Esguerra, A., Heubach, K., Hulme, M., Lidskog, R., Lövbrand, E., Marquard, E., Miller, C., Nadim, T., Neßhöver, C., Settele, J., Turnhout, E., Vasileiadou, E. and Görg, C. (2014). 'Towards a reflexive turn in the governance of global environmental expertise. The cases of the IPCC and the IPBES'. GAIA - Ecological Perspectives for Science and Society 23 (2), pp. 80-87. https://doi.org/10.14512/gaia.23.2.4.

Beck, S., Böschen, S., Kropp, C. and Voss, M. (2013). ‘Jenseits des Anpassungsmanagements. $\mathrm{Zu}$ den Potentialen sozialwissenschaftlicher Klimaforschung'. GAIA - Ecological Perspectives for Science and Society 22 (1), pp. 8-13.

Beck, S. and Mahony, M. (2017). 'The IPCC and the politics of anticipation'. Commentary. Nature Climate Change 7 (5), pp. 311-313. https://doi.org/10.1038/nclimate3264.

Betsill, M. and Pielke, A. (1998). 'Blurring the boundaries - domestic and international ozone politics and lessons for climate change'. International Environmental Affairs 10 (3), pp. 147-172. 
Biello, D. (2007). ‘Conservative climate'. Scientific American 296 (4), pp. 16-19. https://doi.org/10.1038/scientificamerican0407-16.

Boehmer-Christiansen, S. (1994). 'Global climate protection policy: the limits of scientific advice - part 1'. Global Environmental Change 4 (2), pp. 140-159. https://doi.org/10.1016/0959-3780(94)90049-3.

Bolin, B. and Houghton, J. (1995). 'Berlin and global warming policy'. Nature 375 (6528), pp. 176-176. https://doi.org/10.1038/375176a0.

Bray, D. (2010). 'The scientific consensus of climate change revisited'. Environmental Science \& Policy 13 (5), pp. 340-350. https://doi.org/10.1016/j.envsci.2010.04.001.

Cook, J., Nuccitelli, D., Green, S. A., Richardson, M., Winkler, B., Painting, R., Way, R., Jacobs, P. and Skuce, A. (2013). 'Quantifying the consensus on anthropogenic global warming in the scientific literature'. Environmental Research Letters 8 (2), p. 024024. https://doi.org/10.1088/1748-9326/8/2/024024.

Curry, J. A. (2013). 'Kill the IPCC: after decades and billions spent, the climate body still fails to prove humans behind warming'. Financial Post. URL: http://busine ss.financialpost.com/fp-comment/ipcc-climate-global-warming (visited on 21st February 2019).

Curry, J. A. and Webster, P. J. (2011). 'Climate science and the uncertainty monster'. Bulletin of the American Meteorological Society 92 (12), pp. 1667-1682. https://doi.org/10.1175/2011bams3139.1.

Deutsches Klima Konsortium (May 2015). Future prospects of climate research 2015-2025. DKK-position paper. Berlin, Germany.

Edenhofer, O. (2014). 'Cartography of policy path: a new role for science in policy'. In: Stiftung Mercator: Interfaces of science and policy and the role of foundations. Berlin, Germany: Stiftung Mercator, pp. 14-21.

Edwards, P. N. (2010). A vast machine. Computer models, climate data, and the politics of global warming. Cambridge, MA, U.S.A.: MIT Press.

Geden, O. and Fischer, S. (2014). Moving targets. Negotiations on the EU's energy and climate policy objectives for the post-2020 period and implications for the German energy transition. SWP Research Paper. Berlin, Germany: German Institute for International and Security Affairs (SWP).

Geden, O. (2015). 'Policy: Climate advisers must maintain integrity'. Nature 521 (7550), pp. 27-28. https://doi.org/10.1038/521027a.

Griggs, D. (2014). 'Climate policy: streamline IPCC reports'. Nature 508 (7495), pp. 171-173. https://doi.org/10.1038/508171a.

Grundmann, R. (2006). 'Ozone and climate'. Science, Technology, E Human Values 31 (1), pp. 73-101. https://doi .org/10.1177/0162243905280024.

- (2016). 'Climate change as a wicked social problem'. Nature Geoscience 9 (8), pp. 562-563. https://doi.org/10.1038/ngeo2780.

Gupta, J. (2010). 'A history of international climate change policy'. Wiley Interdisciplinary Reviews: Climate Change 1 (5), pp. 636-653. https://doi.org/10.1002/wcc. 67. 
Gupta, J. (2014). 'Global scientific assessments and environmental resource governance: towards a science-policy interface ladder'. In: The role of "experts" in international and european decision-making processes. Advisors, decision makers or irrelevant actors? Ed. by M. Ambrus, K. Arts, E. Hey and H. Raulus. Cambridge, U.K.: Cambridge University Press, pp. 148-170. https://doi.org/10.1017/cbo9781139871365.010.

Haag, A. L. (2008). 'What's next for the IPCC?' Nature Reports Climate Change (0801), pp. 4-6. https://doi.org/10.1038/climate.2007.73.

Hoag, H. (2010). 'How to improve the IPCC'. Nature. https://doi.org/10.1038/news.2010.302.

Hughes, H. (2015). 'Bourdieu and the IPCC's symbolic power'. Global Environmental Politics 15 (4), pp. 85-104. https://doi.org/10.1162/glep_a_00323.

Hughes, H. R. and Paterson, M. (2017). 'Narrowing the climate field: the symbolic power of authors in the IPCC's assessment of mitigation'. Review of Policy Research 34 (6), pp. 744-766. https://doi . org/10.1111/ropr. 12255.

Hulme, M. (2013). 'Lessons from the IPCC: do scientific assessments need to be consensual to be authoritative?' In: Future directions for scientific advice. Centre for Science and Policy, pp. 142-147. https://doi.org/10.13140/RG.2.1.4256.6563.

Hulme, M., Zorita, E., Stocker, T. F., Price, J. and Christy, J. R. (2010). ‘IPCC: cherish it, tweak it or scrap it?' Nature 463 (7282), pp. 730-732. https://doi.org/10.1038/463730a.

Hulme, M. (2010). 'Problems with making and governing global kinds of knowledge'. Global Environmental Change 20 (4), pp. 558-564. https://doi.org/10.1016/j.gloenvcha.2010.07.005.

Jasanoff, S. (2011). 'Cosmopolitan knowledge: climate science and global civic epistemology'. In: The Oxford handbook of climate change and society. Ed. by J. S. Dryzek, R. B. Norgaard and D. Schlosberg. Oxford, U.K.: Oxford University Press, pp. 129-143. https://doi.org/10.1093/oxfordhb/9780199566600.003.0009.

Jones, R. N. (2000). 'Managing uncertainty in climate change projections - issues for impact assessment'. Climatic Change 45 (3/4), pp. 403-419. https://doi.org/10.1023/A:1005551626280.

Kintisch, E. (2013). 'Climate science. For researchers, IPCC leaves a deep impression'. Science 342 (6154), p. 24. https://doi.org/10.1126/science.342.6154.24.

Kowarsch, M., Jabbour, J., Flachsland, C., Kok, M. T. J., Watson, R., Haas, P. M. and et al. (2017). Global environmental assessments and the path to solutions.

Kromrey, H. (2006). Empirische Sozialforschung. Modelle und Methoden der standardisierten Datenerhebung und Datenauswertung. (UTB, 1040). 11th ed. Stuttgart, Germany: Lucius \& Lucius. https://doi.org/10.1007/978-3-322-93463-5.

Luhmann, N. (1989). Ecological communication. Chicago, IL, U.S.A.: University of Chicago Press.

Mahony, M. and Hulme, M. (2016). 'Modelling and the nation: institutionalising climate prediction in the U.K., 1988-92'. Minerva 54 (4), pp. 445-470. https://doi.org/10.1007/s11024-016-9302-0. 
Masood, E. (1996). 'Climate report 'subject to scientific cleansing'. Nature 381 (6583), pp. 546-546. https://doi.org/10.1038/381546a0.

Mastrandrea, M. D., Field, C. B., Stocker, T. F., Edenhofer, O., Ebi, K. L., Frame, D. J., Held, H., Kriegler, E., Mach, K. J., Matschoss, P. R., Plattner, G.-K., Yohe, G. W. and Zwiers, F. W. (2010). 'Guidance note for lead authors of the IPCC fifth assessment report on consistent treatment of uncertainties'. In: IPCC cross-working group meeting on consistent treatment of uncertainties (Jasper Ridge, CA, U.S.A. 6th-7th July 2010). URL: https://archive.ipcc.ch/pdf/supportin g-material/uncertainty-guidance-note.pdf.

Nature (2013). 'The final assessment'. Nature 501 (7467), pp. 281-281. https://doi.org/10.1038/501281a.

Oppenheimer, M., O’Neill, B. C., Webster, M. and Agrawala, S. (2007). 'Climate change. The limits of consensus'. Science 317 (5844), pp. 1505-1506. https://doi.org/10.1126/science.1144831.

Oreskes, N. (2004). 'The scientific consensus on climate change'. Science 306 (5702), pp. 1686-1686. https://doi.org/10.1126/science.1103618.

- (2018). 'The scientific consensus on climate change: how do we know we're not wrong?' In: Climate modelling - philosophical and conceptual issues. Ed. by E. A. Lloyd and E. Winsberg. Basingstoke, U.K.: Palgrave Macmillan, pp. 31-64. https://doi.org/10.1007/978-3-319-65058-6_2.

Pearce, W., Grundmann, R., Hulme, M., Raman, S., Kershaw, E. H. and Tsouvalis, J. (2017). 'Beyond counting climate consensus'. Environmental Communication 11 (6), pp. 723-730. https://doi.org/10.1080/17524032.2017.1333965.

Rahmstorf, S. (23rd September 2013). Der neue IPCC-Klimabericht.

URL: https://www.scilogs.de/klimalounge/der-neue-ipcc-klimabericht (visited on 21st February 2019).

Rödder, S. (2015). 'Science media centres and public policy'. Science and Public Policy 42 (3), pp. 387-400. https://doi.org/10.1093/scipol/scu057.

Rosenberg, S., Vedlitz, A., Cowman, D. F. and Zahran, S. (2010). 'Climate change: a profile of U.S. climate scientists' perspectives'. Climatic Change 101 (3-4), pp. 311-329. https://doi.org/10.1007/s10584-009-9709-9.

Sarewitz, D. (2000). 'Science and environmental policy: an excess of objectivity'. In: Earth matters. The earth science, philosophy, and the claims of community. Ed. by R. Frodeman and V. R. Baker, pp. 79-98.

- (2011). 'The voice of science: let's agree to disagree'. Nature 478 (7367), pp. 7-7. https://doi.org/10.1038/478007a.

Schiermeier, Q. (2011). 'Major reform for climate body'. Nature 473 (7347), pp. 261-261. https://doi.org/10.1038/473261a.

- (2014). 'IPCC report under fire'. Nature 508 (7496), pp. 298-298. https://doi.org/10.1038/508298a.

Schneider, S. H. (2001). 'A constructive deconstruction of deconstructionists: a response to Demeritt'. Annals of the Association of American Geographers 91 (2), pp.338-344. https://doi.org/10.1111/0004-5608.00246.

Schrope, M. (2001). 'Consensus science, or consensus politics?' Nature 412 (6843), pp. 112-114. https://doi.org/10.1038/35084265.

Socolow, R. H. (2011). 'High-consequence outcomes and internal disagreements: tell us more, please'. Climatic Change 108 (4), pp. 775-790. https://doi.org/10.1007/s10584-011-0187-5. 
Solomon, S. and Manning, M. (2008). 'The IPCC must maintain its rigor'. Science 319 (5869), pp. 1457-1457. https: //doi.org/10.1126/science.1155724.

Stocker, T. F. and Plattner, G.-K. (2014). 'Climate policy: rethink IPCC reports'. Nature 513 (7517), pp. 163-165. https : //doi .org/10.1038/513163a.

The Intergovernmental Panel on Climate Change (IPCC) (2018). Organization. URL: https://www.ipcc.ch/organization/organization. shtml (visited on 11th July 2018).

The Norwegian Nobel Institute (2018). The Nobel Peace Prize 2007. Intergovernmental Panel on Climate Change, Al Gore. URL: https://www . nobelprize .org/nobel_pri zes/peace/laureates/2007/ipcc-facts . html (visited on 11th July 2018).

Tollefson, J. (2010). 'Climate panel must adapt to survive'. Nature 467 (7311), pp. 14-14. https://doi.org/10.1038/467014a.

van der Sluijs, J., van Eijndhoven, J., Shackley, S. and Wynne, B. (1998). 'Anchoring devices in science for policy: the case of consensus around climate sensitivity'. Social Studies of Science 28 (2), pp. 291-323. https://doi.org/10.1177/030631298028002004.

Victor, D. (2015). 'Climate change: embed the social sciences in climate policy'. Nature 520 (7545), pp. 27-29. https://doi .org/10.1038/520027a.

Authors

Imke Hoppe; Postdoc at Universität Hamburg, Department of Journalism and Communication Studies, especially Digital Communication and Sustainability; Center for Earth System Research and Sustainability CEN; Reseach interests: Climate Communication; Media Reception and Effects; Political Communication; Sustainability Communication. E-mail: Imke.Hoppe@uni-hamburg.de.

Simone Rödder; Assistant Professor of Sociology at Universität Hamburg, Department of Social Sciences and Center for Earth System Research and Sustainability CEN; Research interests: Sociology of Science, Governance of Science and Technology, Science and Climate Communication, Theory and Practice of Science Journalism. E-mail: simone.roedder@uni-hamburg.de.

How to cite

Hoppe, I. and Rödder, S. (2019). 'Speaking with one voice for climate science - climate researchers' opinion on the consensus policy of the IPCC'. JCOM 18 (03), A04. https:/ / doi.org/10.22323/2.18030204. 